\title{
Biowarfare conspiracy, faith in government, and compliance with safety guidelines during COVID-19: an international study
}

\author{
Olga Khokhlova ${ }^{1,2}$ (D) Nishtha Lamba ${ }^{1} \cdot$ Aditi Bhatia $^{1} \cdot$ Marina Vinogradova $^{2}$
}

Received: 14 November 2020 / Accepted: 13 September 2021 / Published online: 17 September 2021

(C) The Author(s), under exclusive licence to Springer-Verlag GmbH Germany, part of Springer Nature 2021

\begin{abstract}
In light of the coronavirus pandemic, an international study $(\mathrm{N}=1066)$ was conducted to explore the new bioterrorism conspiracy, faith in government, and compliance with public health guidelines related to COVID-19. Hierarchical regressions showed that while general belief in conspiracies decreased faith in government during COVID-19, it increased belief in bioterrorism regarding the coronavirus. Critical thinking was associated with decreased endorsement of biowarfare conspiracy. Higher levels of belief in bioterrorism, faith in government, and perceived risk positively facilitated compliance behavior in public internationally. Interestingly, while people reported 'worrying about others' as their motivation to follow guidelines, 'worrying about self' was most strongly associated with compliance. The implications of these findings are discussed in the light of enhancing compliance with public health guidelines and effective ways of conveying them to an increasingly polarized society.
\end{abstract}

Keywords Conspiracy · Bioweapon · COVID-19 · Faith in government · Public health measures

\section{Introduction}

Large scale events of global relevance are particular targets of conspiracy theorists (Prooijen and Douglas 2017), due to the proportionality bias-the belief that a large and significant event can only be explained by a proportionally large reason (Leman and Cinnirella 2007). The onset of the global COVID-19 pandemic has allowed for

Olga Khokhlova

o.khokhlova@mdx.ac.ae

1 Psychology Department, Middlesex University Dubai, Dubai Knowledge Park - Blocks 4, 16, 17 \& 19, Dubai, United Arab Emirates

2 Psychology Department, Lomonosov Moscow State University, Moscow, Russia 
a whole range of conspiracy theories to emerge, indulging in speculations about the origin, spread, diagnosis, and treatment of the illness. These continue to remain misleading and are often devoid of a sound scientific basis (Craft et al. 2017).

\subsection{The bioterrorism conspiracy: predictors and implications}

Numerous conspiracy theories have emerged during the pandemic, for instance- the link between 5G and coronavirus (Ahmed et al. 2020), the involvement of Bill Gates in causing the pandemic (Shahsavari et al. 2020) and the belief that the virus itself does not exist (Freeman et al. 2020). Of these, the most noteworthy in relation to global governmental influence on healthcare is the belief that the origin and spread of COVID-19 is deliberately engineered as a form of bioterrorism for socio-political advantage. Different conspiracists affiliated with a variety of ideologies report this to be the doing of one or more countries, in this case, bioterrorism is most commonly attributed to the Chinese government (Imhoff and Lamberty 2020; Schild et al. 2020). Globally, belief in biowarfare conspiracy has already resulted in hostility and mistrust, potentially leading to changes in international policies (Ling 2020).

Conspiracy theories may function to decrease anxiety by providing an explanation for seemingly inexplicable phenomenon that is perceived as intriguing or mysterious, while also making individuals feel like they are holders of privileged information and create a sense of belongingness to an in-group with similar ideologies (Cichocka et al. 2015; Swami et al. 2016). However, Prooijen (2020) suggests that conspiracy theories may in fact further contribute to existential anxiety, thus reinforcing conspiratorial thinking when faced with anxiety-inducing events. Believing in a single conspiracy theory has been found to be predictive of belief in a variety of conspiracy-related ideas, which implies that a set of people with shared characteristics may be more susceptible to being influenced by suggestions of connivance (Swami et al. 2010; Prooijen and Acker 2015). Amongst a variety of personality profiles, previous research has shown that higher levels of education (Prooijen 2017), high self-esteem (Cichocka et al. 2015), and critical thinking (Swami et al. 2014) have been associated with lower conspiracist beliefs. Moreover, cognitive sophistication (Pennycook et al. 2020) and trust in science (Plohl and Musil 2021) was predictive of reduced COVID-19 misperceptions. Several research studies have also shown a high correlation between paranoid ideation, paranormal beliefs, schizotypy, and endorsement of conspiracy beliefs such as bioterrorism (Barron et al. 2014; Darwin et al. 2011; Georgiou et al. 2019). At the core of it, both paranoia and the biowarfare theory share a belief in external malicious or predatory intent and mistrust of individuals, organizations or outside forces such as the Chinese government (Larsen et al. 2020).

Findings from a study by Oleksy et al. (2021) indicate that there is a greater need to focus on the content of the COVID-19 conspiracy theories, as those specifically related to the government may have the potential to cause greater harm by fostering public mistrust, in comparison to other general conspiracy beliefs. This is in turn could impact the perceived risk of the virus and the subsequent adherence to public health guidelines, which means that seemingly harmless speculation about the 
origins of the virus, can in fact have disastrous behavioral implications (Imhoff \& Lamberty 2020).

\subsection{Faith in government during the global pandemic}

The rapidly changing guidelines and government measures to manage the spread of the illness have increased individual speculation about the government, subsequently affecting people's faith in their political institutions. The systems justification theory posits that individuals strive to maintain the political status quo, and in the context of the pandemic, increased system justification may promote the endorsement of governmental measures by the public (Cichocka and Jost 2014; Jutzi et al. 2020). In the pre-pandemic world, differences in faith and trust in the government had varying patterns across the globe, depending on national political ideology and censorship (Ward et al. 2016). Cross-cultural differences are apparent, for example-countries such as China, India, Indonesia, UAE, Saudi Arabia and Malaysia have been found to have high trust in their government while, US, Germany, France, Ireland, UK and Russia rank the lowest (De Bruin et al. 2020; Gheorghe 2020). Other reports in line with these views (Fournier et al. 2011; Holbrook 2004 also discussed how countries such as Russia, Canada, Singapore, US and UK held pessimistic views regarding the economic prospects of their country which led to decreasing faith in their government systems.

Political ideologies have already been shown to influence the perceived threat posed by the coronavirus (Calvillo et al. 2020). A pattern of 'conspiratorial style of reasoning', political extremism and psychopathology (Georgiou et al. 2020) is observed in people that have shown conspiracy theory endorsement during the pandemic. Negative attitudes towards government-issued guidelines during the pandemic have also been shown to be associated with individual endorsement of conspiracy beliefs about COVID-19 (Freeman et al. 2020; Georgiou et al. 2020). For example, Oleksy et al. (2021) reported that skepticism towards the government was predictive of lesser engagement with protective measures such as hand washing, while Swami and Barron (2020) found that rejection of COVID-19 conspiracy theories was associated with higher compliance with social distancing measures. It appears that differences in attitudes towards government measures across countries, can be attributed to the overall management of the spread of COVID-19, actual risk posed by the virus (in terms of number of cases relative to population), prepandemic levels of government trust, and national socio-economic inequality (Freeman et al. 2020; Plohl and Musil 2021). However, more research is needed to better understand factors which determine trust in political institutions during such public health emergencies and how it may have changed during the course of the pandemic.

\subsection{Compliance with COVID-19 guidelines}

With the start of the pandemic, countries across the world have put a wide range of guidelines to ensure public safety and to curb the spread of the virus. Unless enforced with strict penalties, compliance to the measures has varied greatly, with 
many downplaying the risks and 'ignoring' the guidelines or contributing to the spread of both the virus and virus-related misinformation (Plohl and Musil 2021). The lack of a mutually agreed understanding of the pandemic has left space for radical polarizing beliefs to emerge, the behavioral manifestations of which can have a devastating effect on the public health measures that are put in place to protect people (Freeman et al. 2020). This may also mean that relying only on fact-based coverage of COVID-19 guidelines by the media, is insufficient and likely to fall on deaf ears, when it comes to individuals prone to conspiracy beliefs. In the current global climate, it is imperative to understand individual motivations to follow guidelines, so that targeted behavioral changes can be elicited. Recent research suggests that motivating factors to follow public health guidelines include-general health beliefs, peer influence, prosocial behavior, estimation of personal vulnerability and fear/perceived threat of the virus (Andrews et al. 2020; Clark et al. 2020). Of these, Harper et al. (2020) have found that the strongest motivator for compliance with safety standards was the personal fear of contracting COVID-19. Further investigation can help establish recommendations for strategies to mitigate the virus (and future outbreaks) and how they are communicated to the public in a way that accounts for individual differences and promotes compliance. Moreover, exploring the cross-cultural differences between governmental attitudes also has implications for adherence to guidelines that can ultimately increase or decrease the spread of the virus across the world (Hasan et al. 2020).

Given the novelty of the current pandemic, this multi-national study was designed to explore several relationships between faith in government during COVID-19, belief in conspiracy theories and bioterrorism, compliance with governmental measures, paranoia and other cognitive factors like critical thinking. The study also aimed to understand country-wise differences in faith in government during the pandemic and endorsement of biowarfare conspiracy using a multi-national sample, and differences between high and low-risk countries in perceived compliance with public health measures. In addition to that, we aimed to understand the most motivating factors for following the guidelines.

\section{Method}

The data for this study was collected in several countries, during the month of July 2020, as part of a larger international study. An online link to the survey was posted on a combination of online platforms such as Facebook, Instagram, Reddit and other open blogs, and the data was collected using convenience and snowball sampling.

\subsection{Participants}

We conducted a power analysis to determine our sample, which suggested that we required a minimum of 362 participants to reduce type II error, have 0.80 power, effect size of at least 0.15 , and p value less than 0.05 for 2 tailed tests. We were also interested in group differences between survey participants in high-risk and low-risk 
countries in perception of compliance with COVID-19 guidelines. To have a power of 0.80 with two-tailed $\alpha$ of 0.05 , we needed 216 participants from high-risk and 233 participants from low-risk counties. Therefore, we decided to collect data until we had at least 466 participants that included at least 233 participants from each risk category. While the primary aim of the study was to offer an international perspective, wherever relevant, we have explored country level differences. We kept the following criteria in mind while administering country-level data collection: feasibility, global population distribution, and attaining a greater inclusion of countries which are usually less represented in psychological sciences (Veillard 2017; Puthillam 2020).

The sample consisted of 1083 participants residing across Asia, Europe, North $\&$ South America and Australia (not nationally representative). Seventeen participants were excluded from the final sample as they were under the age of 18, did not qualify due to duplicate cases, or simply did not consent to the study. The overall sample comprised of 1066 participants $\left(\mathrm{M}_{\mathrm{age}}=33.51, \mathrm{SD}_{\mathrm{age}}=12.43\right.$, range age $=18-83$, males $=409$, females $=651)($ see Table 1$)$. The participants had diverse levels of education, consisting of individuals with a Doctoral-Level Qualification (6\%), Postgraduate qualification (51\%), Undergraduate qualification (33\%) and High School Diploma or lower (10\%). Top eight countries with national samples of at least 30 participants were used for country-wise comparison (India $(n=321)$, Russia $(n=271)$, USA $(n=108)$, UK $(n=79)$, Canada $(n=48)$, Germany $(n=41)$, Australia $(n=31)$, Pakistan $(n=30))$.

\subsection{Materials}

Materials and data are available on the OSF page (OSF, available at https://osf.io/ 5uncm/?view_only=9bf8a3a3b6804ad48f573c8695ada347).

Since there are no standardized questionnaires to assess perceptions related to the pandemic, the authors created a survey to explore perceptions of compliance and its motivating factors, belief in biowarfare theory regarding COVID-19 and faith in government during COVID-19. This was used in combination with standardized questionnaires to measure participants' belief in conspiracies, critical thinking and paranoid ideation. The participants were prompted to bear in mind the COVID-19 pandemic when answering the survey questions.

Belief in biowarfare theory regarding COVID-19 was assessed by three survey questions: "Do you believe that the origin (and not the spread) of this COVID-19 is a form of bioterrorism?", "Do you believe that the spread (and not the origin) of the COVID-19 is a form of bioterrorism?" and "Do you believe that both the origin and spread of the COVID-19 is a form of bioterrorism?". The answers were measured on 5-point Likert scale ranging from 1, 'not at all' to 5, 'absolutely'. The questions displayed good internal consistency, $\alpha=0.81$.

Faith in Government during COVID-19 was measured by the following questions: "Do you think that Governmental measures related to the spread of COVID-19 were adequate?, "Can you say that after COVID-19 you trust the Government less?" and "Can you say that after COVID-19 you trust the Government 
Table 1 Descriptive statistics for demographics, belief in biowarfare, and faith in government during COVID-19 for country level data

\begin{tabular}{|c|c|c|c|c|c|c|c|}
\hline \multirow[t]{2}{*}{ Country } & \multirow[t]{2}{*}{$\mathrm{N}$} & \multicolumn{2}{|l|}{ Age } & \multicolumn{2}{|c|}{ Gender } & \multirow{2}{*}{$\begin{array}{l}\text { Belief in } \\
\text { biowarfare } \\
\text { Mean }\end{array}$} & \multirow{2}{*}{$\begin{array}{l}\text { Faith in govt } \\
\text { Mean }\end{array}$} \\
\hline & & Mean & SD & Male & Female & & \\
\hline India & 321 & 33.91 & 14.16 & 145 & 174 & 9.48 & 8.94 \\
\hline Russia & 271 & 36.26 & 10.20 & 86 & 185 & 7.58 & 6.97 \\
\hline USA & 108 & 34.37 & 14.18 & 47 & 58 & 5.65 & 6.48 \\
\hline UK & 79 & 27.51 & 10.81 & 16 & 62 & 7.94 & 6.62 \\
\hline Canada & 48 & 36.12 & 13.68 & 24 & 24 & 6.10 & 10.30 \\
\hline Germany & 41 & 31.00 & 7.02 & 19 & 22 & 5.51 & 10.65 \\
\hline Australia & 31 & 31.20 & 12.49 & 14 & 17 & 7.13 & 9.73 \\
\hline Pakistan & 30 & 30.00 & 11.33 & 9 & 21 & 9.41 & 8.90 \\
\hline Ukraine & 19 & 37.21 & 9.99 & 1 & 18 & - & - \\
\hline Italy & 16 & 36.13 & 13.21 & 10 & 6 & - & - \\
\hline Belarus & 12 & 28.36 & 4.34 & 2 & 10 & - & - \\
\hline Ireland & 6 & 29,50 & 8,85 & 1 & 5 & - & - \\
\hline Netherlands & 6 & 33,33 & 15,74 & 3 & 3 & - & - \\
\hline Serbia & 6 & 29,67 & 3,62 & 1 & 5 & - & - \\
\hline Cyprus & 4 & 23,75 & 2,22 & 2 & 2 & - & - \\
\hline Singapore & 4 & 22,00 & 2,83 & 1 & 3 & - & - \\
\hline Spain & 4 & 35,00 & 12,08 & 3 & 1 & - & - \\
\hline Belgium & 4 & 28,50 & 3,11 & 2 & 2 & - & - \\
\hline Chile & 3 & 27,00 & 6,25 & 1 & 2 & - & - \\
\hline Finland & 3 & 30,00 & 1,73 & 0 & 3 & - & - \\
\hline France & 3 & 26,33 & 7,51 & 0 & 3 & - & - \\
\hline Israel & 3 & 32,33 & 7,37 & 0 & 3 & - & - \\
\hline Malaysia & 3 & 31,33 & 16,20 & 1 & 2 & - & - \\
\hline Philippines & 3 & 31,00 & 12,73 & 2 & 1 & - & - \\
\hline Turkey & 5 & 31,40 & 9,53 & 2 & 3 & - & - \\
\hline Greece & 2 & 25,00 & 8,49 & 0 & 2 & - & - \\
\hline Hungary & 2 & 25,50 & 3,54 & 1 & 1 & - & - \\
\hline Sri Lanka & 2 & 22,00 &, 000 & 0 & 2 & - & - \\
\hline Poland & 3 & 23,00 &, 000 & 1 & 2 & - & - \\
\hline Kyrgyzstan & 2 & 26,00 & ,000 & 0 & 2 & - & - \\
\hline Argentina & 1 & 20,00 & - & 0 & 1 & - & - \\
\hline Brazil & 1 & 32,00 & - & 1 & 0 & - & - \\
\hline China & 1 & 20,00 & - & 0 & 1 & - & - \\
\hline Croatia & 1 & 21,00 & - & 0 & 1 & - & - \\
\hline Denmark & 1 & 70,00 & - & 1 & 0 & - & - \\
\hline Ghana & 1 & - & - & 1 & 0 & - & - \\
\hline Hong Kong & 1 & 22,00 & - & 0 & 1 & - & - \\
\hline Japan & 1 & 25,00 & - & 1 & 0 & - & - \\
\hline Latvia & 1 & 19,00 & - & 1 & 0 & - & - \\
\hline Kenya & 1 & 22,00 & - & 0 & 1 & - & - \\
\hline
\end{tabular}


Table 1 (continued)

\begin{tabular}{|c|c|c|c|c|c|c|c|}
\hline \multirow[t]{2}{*}{ Country } & \multirow[t]{2}{*}{$\mathrm{N}$} & \multicolumn{2}{|l|}{ Age } & \multicolumn{2}{|c|}{ Gender } & \multirow{2}{*}{$\begin{array}{l}\text { Belief in } \\
\text { biowarfare } \\
\text { Mean }\end{array}$} & \multirow{2}{*}{$\begin{array}{l}\text { Faith in govt } \\
\text { Mean }\end{array}$} \\
\hline & & Mean & $\mathrm{SD}$ & Male & Female & & \\
\hline Mauritius & 1 & 23,00 & - & 1 & 0 & - & - \\
\hline Myanmar & 1 & 23,00 & - & 0 & 1 & - & - \\
\hline New Zealand & 1 & - & - & 1 & 0 & - & - \\
\hline Egypt & 1 & 20,00 & - & 1 & 0 & - & - \\
\hline Bosnia and Herzegovina & 1 & 26,00 & - & 1 & 0 & - & - \\
\hline Sweden & 1 & 29,00 & - & 1 & 0 & - & - \\
\hline Moldova & 1 & 38,00 & - & 0 & 1 & - & - \\
\hline Uzbekistan & 1 & 26,00 & - & 0 & 1 & - & - \\
\hline Kazakhstan & 2 & 46,00 &, 000 & 0 & 2 & - & - \\
\hline Bangladesh & 1 & 24,00 & - & 1 & 0 & - & - \\
\hline
\end{tabular}

more?". The questions were answered on 5-point Likert-scale ranging from 1, 'not at all' to 5, 'absolutely'. Second item was reverse-scored attention check question. These survey questions have also shown excellent internal consistency, $\alpha=0.95$.

Critical Thinking Disposition Scale (Sosu 2013): This scale was administrated to assess critical thinking. It has 11 items (e.g., "I usually check the credibility of the source of information before making judgements"). The scale is scored using a 5-point Likert-type responses $(1=$ strongly disagree, $5=$ strongly agree). Internal consistency was good, $\alpha=0.90$.

Generic Conspiracy Beliefs Scale (Brotherton et al. 2013): This was used to measure conspiracy beliefs. It consists of 15 items (e.g., "The government is involved in the murder of innocent citizens and/or well-known public figures, and keeps this a secret"). The answers were measured using scale a 5-point Likerttype scale (1: definitely not true; 5: definitely true). Higher scores indicate greater belief in conspiracy. The scale showed excellent reliability, $\alpha=0.94$.

Paranoia scale (Fenigstein and Vanable 1992): This scale was used to assess paranoid ideation and it consists of 20 items, for example, "It is safer to trust no one". The scale was scored using a 5-point Likert-type scale ranging from 1, not at all applicable to me, to 5, extremely applicable to me, with higher scores indicating greater paranoia. The scale showed good internal consistency, $\alpha=0.92$.

Perception of compliance with COVID-19 guidelines was measured by asking participants "Generally, do you believe you are following safety guidelines more than others in your community?", which was answered using 5-point Likert response scale ranging from 1, 'much less than others' to 5, 'much more than others'.

In addition to the above, participants were asked to complete one multiple choice question: "Which motivating, or guilt factor makes you follow the guidelines?". This question was designed to provide additional information regarding the participants' motivation to follow public health guidelines. 


\section{Results}

Statistical analyses were performed using SPSS software ver. 23.0 (IBM, Armonk, NY, USA). We have primarily administered three hierarchical regressions in the present study to explore factors predicting belief in biowarfare theory, faith in government, compliance. These models accounted for demographic characteristics. This analysis was also chosen to show the contribution of each set of variables by comparing the models (VandenBos, 2007). Means scores, t-tests, and correlations were further used to explore compliance from different perspectives.

\subsection{Factors predicting belief in biowarfare theory regarding COVID-19}

The effects of critical thinking, belief in conspiracy theories and paranoia on belief in biowarfare theory regarding COVID-19 were analyzed for international level data using hierarchical regression analysis in which demographic variables (age, gender, level of education) were entered in Model 1, and the three predictor variables were entered in Model 2 (Table 2).

Demographic variables did not significantly predict belief in biowarfare in regard to COVID-19 $(F(3,829)=0.611, p>0.05)$. Model 2 , in which critical thinking, general beliefs in conspiracy and paranoia were added to the regression model, was significant $\left(\Delta R^{2}=0.281\right),(F(6,829)=59.905, p<0.01)$. As can be seen in Table 2 , two out of three variables were significant $(p<0.01)$. Critical thinking predicts decreased belief in biowarfare theory regarding COVID-19, general belief in conspiracy is a positive predictor of belief in biowarfare theory regarding COVID-19. Paranoia was not found to be a significant predictor of belief in biowarfare theory regarding COVID-19 ( $p>0.05)$.

Amongst the top eight countries in the sample, comparison of means showed that India and Pakistan had the highest level of bioterrorism belief; Russia, UK and Australia had medium belief in bioterrorism; USA, Canada and Germany had the lowest belief in biowarfare theory regarding COVID-19 (see Table 1).

\subsection{Factors predicting faith in government during COVID-19}

First effects of critical thinking, belief in conspiracy theories and paranoia on faith in government during COVID-19 were analyzed for international level data using hierarchical regression analysis in which gender, age and level of education were entered first, in Model 1, and the three predictor variables were entered in Model 2.

The results of hierarchical regression analysis are displayed in Table 2. Demographic variables predict faith in government during COVID-19 ( $F$ (3, $824)=12.874, p<0.01$ ) and explain $4.1 \%$ of variance in faith in government. Higher age $(p=0.001)$ and lower level of education $(p=0.02)$ were associated with increased faith in government as indicated by the positive and negative regression weights respectively. Men were found to have higher faith in government $(p<0.01)$ 
Table 2 Hierarchical regression models for biowarfare conspiracy regarding COVID-19 and faith in Government during COVID-19

Model and predictors

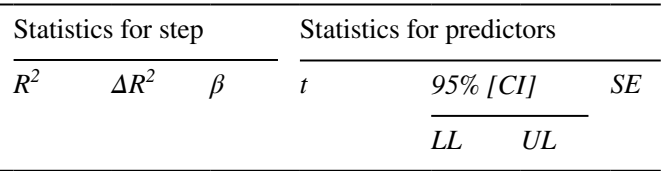

Hierarchical regression1

DV: Biowarfare theory in regard to COVID-19

Model 1

Age

Gender $(1=$ female $)$

Educational level (1 = Incomplete School Education)

Model 2

Critical thinking

General belief in conspiracy

Paranoia

Hierarchical regression 2

DV: Faith in government during COVID-19

Model 1

Age

Gender $(1=$ female $)$

Educational level (1 = Incomplete School Education)

Model 2

Critical thinking

General belief in conspiracy

Paranoia

Hierarchical regression 3

Model 1

Age

Gender $(1=$ female $)$

Educational level (1 = Incomplete School Education)

Model 2

General belief in conspiracy

Belief in bioterrorism

Model 3

Interaction

$* * p<.01, * p<.05$

$D V$ dependent variable

than women as indicated by positive regression weight. Next, three main variables were entered to the regression model (Step 2 ). This model was highly significant $\left(\Delta R^{2}=0.072\right),(F(6,824)=11.592, p<0.01)$. However, only greater general belief

$\begin{array}{lllll}.025 & .656 & -.016 & .032 & 0.12 \\ .024 & .668 & -.401 & .743 & .291 \\ -.039 & -1.060 & -.103 & .466 & .145\end{array}$

$.286 * * .281 * *$

$\begin{array}{lllll}-.179 & -5.967 * * & -.135 & -.068 & .017 \\ .532 & 15.976 * * & .140 & .179 & .010 \\ .005 & .135 & -.015 & .018 & .009\end{array}$

$.045 * * .041 * *$

$\begin{array}{lllll}.125 & 3.353 * * & .014 & .053 & .010 \\ .150 & 4.277 * * & .545 & 1.472 & .236 \\ -.085 & -2.340 * & .062 & .522 & .117\end{array}$

$.078 * * .072 * *$

$$
\begin{array}{lllll}
-.056 & -1.654 & -.059 & .005 & .016 \\
-.175 & -4.604 * * & -.061 & -.024 & .009 \\
.015 & .371 & -.013 & .019 & .008
\end{array}
$$

$$
\begin{array}{rrrrrr}
.015^{* *} .015^{* *} & & & & & \\
& -.026 & -.740 & -.008 & .004 & .003 \\
& -.044 & -1.31 & -.226 & .045 & .069 \\
& -.100 & -2.89 & -.166 & -.031 & .034
\end{array}
$$

$.020 * * .005 * *$

$$
\begin{array}{lllll}
-.059 & -1.524 & -.010 & .001 & .003 \\
.082 & 2.162 * * & .002 & .040 & .010
\end{array}
$$$$
019 * * .005 * *
$$ 
in conspiracy was a significant predictor $(p<0.01)$ of decreased faith in government during COVID-19, contributing an additional variance of $7 \%$ to the model.

Country level comparisons showed that Canada, Germany and Australia displayed highest level of faith in government during the pandemic, India and Pakistan showed medium level, whereas Russia, USA and UK had the lowest level of faith in government (see Table 1).

\subsection{Exploring factors facilitating compliance with COVID-19 guidelines}

\subsubsection{Hierarchical regression with general belief in conspiracies, belief in biowarfare, and interaction between general belief in conspiracies and belief in biowarfare}

The first model, with demographic characteristics, was significant $F(3,909)=4.54$, $p=0.004$, explaining a variance of $1.5 \%$. The second model with general belief in conspiracies and belief in bioterrorism, was also significant, $F(5,909)=3.72$, $p=0.002$ explaining a small additional variance of $0.05 \%$. The interaction, between general belief in conspiracies and bioterrorism, also significantly added to the model, $F(6,909)=3.91, p=0.001$, contributing a variance of $0.05 \%$. Individual coefficients in the final model suggest lower levels of education $(p=0.004)$ and greater belief in bioterrorism $(p=0.005)$ increased likelihood of compliance. General belief in conspiracies was not a significant predictor. The interaction, however, was significant $(p=0.03)$, indicating that greater general belief in conspiracies reduced the effect of belief in biowarfare on compliance attitude.

\subsubsection{Faith in government}

Greater faith in government related to the pandemic significantly correlated with the perception of compliance with COVID-19 guidelines $(\mathrm{r}(1064)=0.073, p=0.018)$.

\subsubsection{Difference in compliance attitudes between high and low-risk countries}

As per World Health Organization statistics ( $1^{\text {st }}$ August, 2020), countries from the top ten in terms of overall number of cases were referred as high-risk countries, the rest-as low-risk countries. USA, India, Russia, Chile, Brazil and UK were coded as high-risk countries $(N=781)$, and other countries-as low-risk $(N=282)$. An independent t-test was administered to examine if high and low risk countries differed in their attitudes towards following COVID-19 related governmental guidelines. It was found that people living in high-risk countries $(M=3.78, S D=1.00)$ tend to believe that they are following guidelines more than others in their community as compared to people living in low-risk countries $(M=3.52, S D=1.04),(t(1061)=-3.707$, $p<0.01$, Cohen's d $=0.25,95 \%$ CI $[-0.41,-0.13])$. 


\subsubsection{Motivation factors for compliance}

Frequencies of responses are as follows: (1) worrying about relatives $(N=622),(2)$ worrying about others $(N=556,(3)$ worrying about self $(N=520)$, (4) compliance with guidelines $(N=341),(5)$ worrying about being fined $(N=82)$. The top three motivating factors were then correlated with compliance attitude with COVID-19 guidelines, to identify strongest factors. All factors significantly correlate with compliant behavior $(p<0.01)$, however the ranking of correlation was reversed, with worrying about self, having the highest correlation $(r(518)=0.303, p<0.01)$, followed by worrying about others $(r(554)=0.229, p<0.01)$, whereas worrying about relatives has the lowest correlation $(r(620)=0.131, p<0.01)$ with perception of compliance.

\section{Discussion}

The aims of the present study were threefold. In the context of COVID-19 pandemic, it explored factors associated with newly emerged biowarfare conspiracy theory, pandemic related faith in government, and compliance to safety regulations.

The findings suggest that age, gender and level of education did not predict COVID-19 related belief in biowarfare, which contradicts previous literature suggesting that higher level of education is associated with lower general conspiracy beliefs (Georgiou et al. 2019; Prooijen 2017). Past research suggests that cognitive sophistication and critical thinking having been found to impact beliefs in conspiracy (Pennycook et al. 2020; Swami et al. 2014), and the findings of this study confirm that critical thinking predicts decreased belief in bioterrorism. The findings are also in line with a large body of literature suggesting that people usually held beliefs in multiple conspiracies at the same time (Swami et al. 2010; rooijen and Acker 2015), which is of particular relevance given the nature and scale of the ongoing pandemic. We found that previously held general belief in conspiracy theories was predictive of believing in the newly emerged COVID-19 biowarfare theory. This is concerning as initial research suggested that belief in conspiracy provide a simple explanation for complex events and was associated with feelings of powerlessness (Cichocka et al. 2015; Hofstadter 1965). Moreover, despite the idea that conspiracy theories can help with anxiety reduction, some research suggests that conspiracy theories might be the source of existential threat and, as a result, of more anxiety (Prooijen 2020).

It was further found that amongst top eight countries in the sample, India and Pakistan were characterized as having highest belief in biowarfare conspiracy, Russia, Australia and UK-medium level, and USA, Canada and Germany the lowest level of belief in bioterrorism. These differences might be explained by proximity to China, previous history of bilateral relationships, or national media coverage of COVID-19.

In regard to faith in government during COVID-19, findings indicate that older people tend to trust government more, which could be explained by an overall tendency to have higher institutional trust with age (Hudson 2006). Men also showed higher trust in the government during COVID-19, compared to women. This reflects 
previously established gender differences regarding trust in government (Edelman Trust Barometer 2020) and might be explained by the unequal gender representation in politics and traditionality, where men show higher engagement with and interest in politics. Lower level of education was associated with increased faith in government during COVID-19, which may be a reflection of critical awareness. Surprisingly, critical thinking was not found to be associated with faith in government during COVID-19. Lewis and Weigert (1985) suggest that trust has three levels: cognitive, emotional and behavioral. It can be assumed that in current situation, trust in government has less of cognitive and more of emotional and behavioral components.

General belief in conspiracy theory was found to be a negative predictor of faith in government. Thus, current attitude towards government is impacted by the public's general belief in conspiracies and could also be a result of non-efficient communication between official institutions and the public. We examined faith in government during COVID-19 in eight countries from the sample and compared their scores with pre-COVID-19 trust in government (Edelman Trust Barometer 2020). While Russia, UK and USA traditionally ranked the lowest, and had a similar trend before the pandemic they continued to show a similar trend during the pandemic (De Bruin et al. 2020; Gheorghe 2020). However, countries like Germany, Australia and Canada, which are usually categorized as having low faith in government (Edelman Trust Barometer 2020), showed increased faith in government during the pandemic, which might be attributed to the way in which the situation was handled in terms of the speed and effectiveness of public health measures. In addition to that, faith in government might have also been impacted by upcoming political events such as presidential elections in the USA and voting for constitutional changes in Russia. Very low survey scores in faith in government among Russian participants can also be explained by the high level of disillusionment with the political system, often discussed regarding post-Communist countries (Cichocka and Jost 2014).

Unlike previous findings (Darwin et al. 2011), paranoia levels of the public during COVID-19 did not significantly contribute towards believing that the pandemic is a form of biowarfare or lower levels of faith in government. Hence, it could be argued, that the pandemic may not have successfully discriminated between those with or without higher levels of paranoia, as early findings suggest an overall increase in paranoid ideation across the world (Larsen et al. 2020). Thus, belief in biowarfare theory as well as changing dynamics of faith in government are social, rather than personal phenomena.

The understanding of the public's conceptualization of this pandemic and endorsement of conspiracy theories are crucial, because they can impact compliant behavior. In current times, unwillingness to follow official guidelines can put further pressure on already struggling health care systems. Unlike previous literature, which suggests that government-related conspiracies were associated with less willingness to use preventive methods, such as social distancing and handwashing (Oleksy et al. 2021), we did not find any association between general belief in conspiracies and compliance attitude during the pandemic. Instead, we found that belief in COVID19 being a biowarfare was associated with higher likelihood of compliance towards health protection behaviour. This finding is also not in line with previous research, 
which suggests that COVID-19 conspiracy beliefs negatively correlate with healthprotective behaviours (Allington et al. 2020; Romer and Jamieson 2020). This can be explained by the content of this particular conspiracy belief, as it does not deny or downplay the severity of the pandemic, but rather indicates higher personal risks and may even encourage hypervigilance (Georgiou et al. 2019). It was further found that people who generally believed in conspiracies more and felt that COVID-19 is a form of biowarfare, complied less with safety guidelines, indicating that higher general belief in conspiracies weakened the positive relationship between belief in biowarfare and compliance. However, given these models explained a very small variance in compliance attitude, these findings should be interpreted with caution.

Given the important role of governments in managing the pandemic, we explored whether faith in government facilitates compliance behaviour. In line with the systems justification theory (Cichocka and Jost 2014), it was further found that firmer belief in government at this time of crises is essential, as it increases the likelihood of the public following safety measures, as our findings suggest and as discussed by the previous research (Bargain and Aminjonov 2020). However, given the sample size and relatively weak relationship between the variables, these findings should also be interpreted with caution. At the same time, since this study explores an important area, further research should examine compliance deferred in terms of faith in political systems.s

Public perception of compliant behavior differed based on the level of risk posed by the pandemic across various countries. This level of analysis seems to be more adequate compared to country-level analysis because instead of grouping countries based on cultural similarities, this grouping was done using official objective data. In comparison to people living in low-risk countries, people in high-risk countries tend to believe that they are following official guidelines more than others. It might be explained by the fact that higher perceived threat induces greater instinct to survive (Mobbs et al. 2015), resulting in compliance to safety measures. For people who are following guidelines, a downward social comparison to others who are maintaining risks (by not wearing masks, for example) could lead to further endorsement of the belief that they themselves are better at compliance.

The understanding of factors that contribute to adherence to guidelines, is imperative to drive the type of messaging used when communicating governmental guidelines and in official news reports. As for now, most of the national slogans that aim to communicate safety measures are based on inducing prosocial behavior, for instance "Wear a mask, save a life" (Russon 2020). When asked about motivating factors of following guidelines, most frequently articulated reason for following official guidelines, in the present study, was worrying about close relatives followed by worrying about others. Surprisingly, when examining the relationship between compliant behavior and motivating factors, it was found that 'worrying about oneself' was most closely related with willingness to follow guidelines. This discrepancy might be attributed to social desirability, as the official guidelines are more "prosocial' in nature than they are clear about individual risks. These findings are in line with previous research showing that fear of contracting COVID-19 is the strongest motivator of individual compliance (Harper et al. 2020). Our findings also add to 
existing research that suggests that risk to oneself and risk of death explain nonnormative prevention behaviours (Marinthe et al. 2020).

This study provides several original contributions to the emerging literature around psychological factors and their role in the COVID-19 pandemic. Not only different predictors of new biowarfare theory and changing dynamics in faith in government during pandemic were analyzed, but it also analyzed behavioral consequences as well as motivating factors for compliant behavior, which are vital during a healthcare crisis of such scale and their understanding can be very helpful in the efficient conveyance of official information. However, recruiting larger national samples in other countries, as well as pre lockdown measurements of faith in government would have further enhanced the existing findings. Given the exploratory nature of the study, we have presented country level comparisons. However, due to the limitations of representativeness, we refrained from (a) administering inferential statistics and making generalisations, and (b) confirmatory analyses on our questionnaires leading to potentially lack of measurement invariance. Future research could aim for more balanced representation of countries for country-level comparison and explore cultural implications of these differences. Another limitation of the study is the convenience sampling method, as it limits generalizability leading to potentially biased results. However, given that data collection took place during strict lockdowns in many counties, with limited opportunities for random or other types of sampling, it appears that the given circumstances justified the use of convenience sampling.

In addition to that, the current study demonstrates country level differences for trust in biowarfare conspiracy as well as faith in government during COVID-19. This together with the finding suggesting that the most motivating factor for following the guidelines is not the same as usually admitted reasons seem to be very important findings in the times of pandemic, with the prevalence of global guidelines and unified messages from official institutions. Thus, this study suggests that having regulations that are customized to the mindsets of people and balanced between individual risks and pro-social behavior might increase the willingness to follow official guidelines.

Future research can explore ways of communicating guidelines more effectively to those who may be most resistant to adhering to them, instead of assuming compliance. Knowing more about factors that might impact endorsement of different conspiracies that accompany large-scale events, as well as understanding of the true motivating factors to follow official guidelines, is essential for the future, should we inevitably face another global problem of this scale.

Funding Nothing to declare.

\section{Declarations}

Conflict of interest The authors declare that there are no conflicts of interest with respect to the authorship or the publication of this article. The work is original, has not been published before, nor is it currently under consideration for publication elsewhere. 
Consent to participate Participants signed the consent form that included the following statement "I have understood the details of the research as explained to me by the researchers and confirm that I have consented to act as a participant."

Consent for publication Consent form included the following statement "I further understand that the data I provide may be used for analysis and subsequent publication, and provide my consent that this might occur."

\section{References}

Ahmed W, Vidal-Alaball J, Downing J, Seguí FL (2020) COVID-19 and the 5G conspiracy theory: social network analysis of Twitter data. J Med Internet Res. https://doi.org/10.2196/19458

Allington D, Duffy B, Wessely S, Dhavan N, Rubin J (2020) Health-protective behaviour, social media usage and conspiracy belief during the COVID-19 public health emergency. Psychol Med. https:// doi.org/10.1017/S003329172000224X

Andrews JL, Foulkes L, Blakemore SJ (2020) Peer influence in adolescence: public-health implications for COVID-19. Trends Cogn Sci 24(8):585-587. https://doi.org/10.1016/j.tics.2020.05.001

Bargain O, Aminjonov U (2020) Trust and compliance to public health policies in times of COVID-19. J Pub Econ 192:104316. https://doi.org/10.1016/j.jpubeco.2020.104316

Barron D, Morgan K, Towell T, Altemeyer B, Swami V (2014) Associations between schizotypy and belief in conspiracist ideation. Personal Individ Differ 70:156-159. https://doi.org/10.1016/j.paid. 2014.06.040

Brotherton R, French CC, Pickering AD (2013) Measuring belief in conspiracy theories: the generic conspiracist beliefs scale. Front Psychol 4:279. https://doi.org/10.3389/fpsyg.2013.00279

Calvillo DP, Ross BJ, Garcia RJ, Smelter TJ, Rutchick AM (2020) Political ideology predicts perceptions of the threat of covid-19 (and susceptibility to fake news about it). Social Psychol Personal Sci 11(8):1119-1128. https://doi.org/10.1177/1948550620940539

Cichocka A, Jost JT (2014) Stripped of illusions? Exploring system justification processes in capitalist and post-communist societies. Int J Psychol 49(1):6-29. https://doi.org/10.1002/ijop.12011

Cichocka A, de Zavala AG, Marchlewska M, Olechowski M (2015) Grandiose delusions: collective narcissism, secure in-group identification, and belief in conspiracies. In: Bilewicz M, Cichocka A, Soral W (eds) The psychology of conspiracy. Taylor \& Francis Group/Routledge, New York, pp 42-61

Cichocka A, Marchlewska M, De Zavala AG (2016) Does self-love or self-hate predict conspiracy beliefs? Narcissism, self-esteem, and the endorsement of conspiracy theories. Social Psychol Personal Sci 7(2):157-166. https://doi.org/10.1177/1948550615616170

Clark C, Davila A, Regis M, Kraus S (2020) Predictors of COVID-19 voluntary compliance behaviors: an international investigation. Glob Trans 2:76-82. https://doi.org/10.1016/j.glt.2020.06.003

Craft S, Ashley S, Maksl A (2017) News media literacy and conspiracy theory endorsement. Commun Pub 2(4):388-401. https://doi.org/10.1177/1948550615616170

Craig A, Satchell., Fido D., and Latzman D., (2020) Functional fear predicts public health compliance in the COVID-19 pandemic. Int J Ment Heal Addict. https://doi.org/10.1007/s11469-020-00281-5

Darwin H, Neave N, Holmes J (2011) Belief in conspiracy theories. The role of paranormal belief, paranoid ideation and schizotypy. Personal Indiv Differ 50(8):1289-1293

De Bruin YB, Lequarre AS, McCourt J, Clevestig P, Pigazzani F, Jeddi MZ, Goulart M (2020) Initial impacts of global risk mitigation measures taken during the combatting of the COVID-19 pandemic. Saf Sci. https://doi.org/10.1016/j.ssci.2020.104773

Edelman Trust Barometer (2020) Global Report. 20th Annual Edelman Trust Barometer. Retrieved 1 August 2020 from https:/www.edelman.com/sites/g/files/aatuss191/files/2020-01/2020\%20Ede 1man\%20Trust\%20Barometer\%20Global\%20Report_LIVE.pdf

Fenigstein A, Vanable PA (1992) Paranoia and self-consciousness. J Pers Soc Psychol 62(1):129. https:// doi.org/10.1037/0022-3514.62.1.129

Fournier P, Van der Kolk H, Carty RK, Blais A, Rose J (2011) When citizens decide: lessons from citizen assemblies on electoral reform. Oxford University Press 
Freeman D, Waite F, Rosebrock L, Petit A, Causier C, East A, Bold E (2020) Coronavirus conspiracy beliefs, mistrust, and compliance with government guidelines in England. Psychol Med. https://doi. org/10.1017/S0033291720001890

Georgiou N, Delfabbro P, Balzan R (2019) Conspiracy beliefs in the general population: the importance of psychopathology, cognitive style and educational attainment. Personal Individ Differ. https://doi. org/10.1016/j.paid.2019.109521

Georgiou N, Delfabbro P, Balzan R (2020) COVID-19-related conspiracy beliefs and their relationship with perceived stress and pre-existing conspiracy beliefs. Personal Individ Differ. https://doi.org/10. 1016/j.paid.2020.110201

Gheorghe R (2020) Fragmentation of trust. Economic growth, social inequality and the new interface of the individual fears. Internal Audit Risk Manag 58(2):54-63

Harper CA, Satchell LP, Fido D, Latzman RD (2020) Functional fear predicts public health compliance in the COVID-19 pandemic. Int J Ment Heal Addict. https://doi.org/10.1007/s11469-020-00281-5

Hasan A, Yim D, Khuntia J (2020) Citizens' adherence to COVID-19 mitigation recommendations by the government: a 3-country comparative evaluation using web-based cross-sectional survey data. J Med Internet Res. https://doi.org/10.2196/20634

Hofstadter R (1965) The paranoid style in American politics and other essays. Knopf, New York

Holbrook RA (2004) Trust in Government. In: Geer, JG (ed.) Public Opinion and Polling around the World: A Historical Encyclopedia. Santa Barbara, CA: ABC-CLIO. Available at: http://ezproxy. macewan.ca/login?url=http://search.credoreference.com/content/entry/abcopinion/trust_in_gover nment/0?institutionId=2632 (accessed 20 October 2020)

Hudson J (2006) Institutional trust and subjective well-being across the EU. Kyklos 59(1):43-62. https:// doi.org/10.1111/j.1467-6435.2006.00319.x

Imhoff R, Lamberty P (2020) A Bioweapon or a Hoax? The link between distinct conspiracy beliefs about the coronavirus disease (COVID-19) outbreak and pandemic behavior. Social Psychol Personal Sci. https://doi.org/10.1177/1948550620934692

Jutzi CA, Willardt R, Schmid PC, Jonas E (2020) Between conspiracy beliefs, ingroup bias, and system justification: how people use defense strategies to cope with the threat of COVID-19. Front Psychol 11:578586. https://doi.org/10.3389/fpsyg.2020.578586

Larsen EM, Donaldson K, Mohanty A (2020) Conspiratorial thinking during COVID-19: the roles of paranoia, delusion-proneness, and intolerance to uncertainty. https://doi.org/10.31234/osf.io/mb65f

Leman PJ, Cinnirella M (2007) A major event has a major cause: evidence for the role of heuristics in reasoning about conspiracy theories. Soc Psychol Rev 9(2):18-28

Lewis JD, Weigert A (1985) Trust as a social reality. Soc Forces 63(4):967-985. https://doi.org/10.1093/ sf/63.4.967

Ling J (2020) The Wuhan virus is not a lab-made Bioweapon. Foreign Policy. https://foreignpolicy.com/ 2020/01/29/coronavirus-china-lab-mortality-virology-wuhan-virus-not-bioweapon/

Marinthe G, Brown G, Delouvée S, Jolley D (2020) Looking out for myself: Exploring the relationship between conspiracy mentality, perceived personal risk, and COVID-19 prevention measures. Br J Health Psychol 25(4):957-980. https://doi.org/10.1111/bjhp.12449

Mobbs D, Hagan CC, Dalgleish T, Silston B, Prévost C (2015) The ecology of human fear: survival optimization and the nervous system. Front Neurosci 9:55. https://doi.org/10.3389/fnins.2015.00055

Oleksy T, Wnuk A, Maison D, Łyś A (2021) Content matters. Different predictors and social consequences of general and government-related conspiracy theories on COVID-19. Personal Indiv Diff. https://doi.org/10.1016/j.paid.2020.110289

Pennycook G, McPhetres J, Zhang Y, Lu JG, Rand DG (2020) Fighting COVID-19 misinformation on social media: experimental evidence for a scalable accuracy-nudge intervention. Psychol Sci 31(7):770-780. https://doi.org/10.1177/0956797620939054

Plohl N, Musil B (2021) Modeling compliance with COVID-19 prevention guidelines: the critical role of trust in science. Psychol Health Med 26(1):1-12. https://doi.org/10.1080/13548506.2020.1772988

Puthillam A (2020) Too WEIRD, Too Fast: preprints about COVID-19 in the Psychological Sciences. https://doi.org/10.31234/osf.io/5w7du

Romer D, Jamieson KH (2020) Conspiracy theories as barriers to controlling the spread of COVID-19 in the US. Soc Sci Med 263:113356. https://doi.org/10.1016/j.socscimed.2020.113356

Russon M (2020) If it saves a life, wearing a mask is worth it'. BBC, United Kingdom

Schild L, Ling C, Blackburn J, Stringhini G, Zhang Y, Zannettou S (2020) Go eat a bat, Chang!: an early look on the emergence of sinophobic behavior on web communities in the face of covid-19 
Shahsavari S, Holur P, Wang T, Tangherlini TR, Roychowdhury V (2020) Conspiracy in the time of corona: automatic detection of emerging COVID-19 conspiracy theories in social media and the news. J Comput Soc Sci 3(2):279-317. https://doi.org/10.1007/s42001-020-00086-5

Sosu EM (2013) The development and psychometric validation of a critical thinking disposition scale. Think Skills Creat 9:107-119. https://doi.org/10.1016/j.tsc.2012.09.002

Swami V, Barron D (2020) Analytic thinking, rejection of coronavirus (COVID-19) conspiracy theories, and compliance with mandated social-distancing: direct and indirect relationships in a nationally representative sample of adults in the United Kingdom. https://doi.org/10.31219/osf.io/nmx9w

Swami V, Chamorro-Premuzic T, Furnham A (2010) Unanswered questions: a preliminary investigation of personality and individual difference predictors of 9/11 conspiracist beliefs. Appl Cogn Psychol 24(6):749-761

Swami V, Furnham A, Smyth N, Weis L, Lay A, Clow A (2016) Putting the stress on conspiracy theories: examining associations between psychological stress, anxiety, and belief in conspiracy theories. Personal Individ Differ 99:72-76. https://doi.org/10.1016/j.paid.2016.04.084

Swami V, Voracek M, Stieger S, Tran US, Furnham A (2014) Analytic thinking reduces belief in conspiracy theories. Cognition 133(3):572-585. https://doi.org/10.1016/j.cognition.2014.08.006

VandenBos GR (2007) APA dictionary of psychology. American Psychological Association

Van Prooijen JW (2017) Why education predicts decreased belief in conspiracy theories. Appl Cogn Psychol 31(1):50-58. https://doi.org/10.1002/acp.3301

Van Prooijen JW (2020) An existential threat model of conspiracy theories. Eur Psychol 25(1):16-25

Van Prooijen JW, Acker M (2015) The influence of control on belief in conspiracy theories: conceptual and applied extensions. Appl Cogn Psychol 29(5):753-761. https://doi.org/10.1002/acp.3161

Van Prooijen JW, Douglas K (2017) Conspiracy theories as part of history: the role of societal crisis situations. Mem Stud 10(3):323-333. https://doi.org/10.1177/1750698017701615

Veillard N (2017) WEIRD sampling in cross-cultural psychology, should it not be less WEIRD and more representative. Unpublished master's thesis. Leiden University, Leiden, Netherlands

Ward PR, Miller E, Pearce AR, Meyer SB (2016) Predictors and extent of institutional trust in government, banks, the media and religious organisations: evidence from cross-sectional surveys in six asia-pacific countries. PLoS ONE. https://doi.org/10.1371/journal.pone.0164096

World Health Organization (2020) WHO Coronavirus Disease (COVID-19) Dashboard, 1 August. https:// covid19. who.int/table

Publisher's Note Springer Nature remains neutral with regard to jurisdictional claims in published maps and institutional affiliations. 